\title{
Making Progress: The Use Of Multiple Progress Reports To Enhance Advertising Students’ Media Plan Term Projects
}

Gary H. Kritz, (E-mail: kritzgar@shu.edu), Seton Hall University Héctor R. Lozada, (E-mail: lozadahe@shu.edu), Seton Hall University Mary M. Long, (E-mail: mlong@pace.edu), Pace University

\begin{abstract}
Since the AACSB mandates that students demonstrate effective oral and written communication skills, it is imperative that business professors do what is necessary to improve such skills. The authors investigate whether the use of using multiple progress reports in an Advertising class project improves the final product. The data results show that grades are improved and satisfaction with the class is enhanced when these multiple progress reports are utilized in a term project.
\end{abstract}

\section{INTRODUCTION}

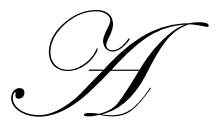

ccording to McBane (2006), AACSB International -the Association to Advance Collegiate Schools of Business, now requires that written and oral communication skills be included within the curriculum as an important characteristic for student learning. AACSB International further states that collegiate faculties are responsible for setting learning goals within their schools for student learning and that making these learning goals operational through actual measurement is a necessary part for student assessment (AACSB International, pp. 59-60). AACSB international asserts that course-embedded measurement is necessary in order to produce graduates with a particular knowledge or abilities specified in the school's learning goals. For example, a school that has a written communication learning goal might specify that a particular course will have required writing exercises in it. Such exercises could serve the assessment needs of the course and also provide the school with assurance that students meet the learning goal in written communication. In addition, the measurements must be a mandated part of the course (AACSB International 2005, p. 62).

Within this context, our schools have taken initiatives to attempt to try and improve the written and oral communication skills of our students. We have even developed a new Business Communication course that the Business Faculty designed and the English Department teaches for our students. This course is in addition to the Humanities and English writing courses that the university requires of all of its students. The faculty developed it because we felt the majority of our Business students' grammar, usage, and other writing skills were never mastered in their elementary and secondary schools and in their other college courses.

It is within this written communication learning goal context that the following was questioned, designed, and developed- as an advertising instructor, how do you prepare students for careers in advertising when the students typically only take one Advertising course, if at all, as required in their marketing major? It is a daunting task because our personal philosophy is to have them do something for a class project that they can show a recruiter on a job interview. Their output should demonstrate their understanding of advertising and their ability to create work, account-wise or creative-wise, that is compelling and effectively written. The students only have about 13 weeks to complete the project in a group. In the real world, this is not an adequate period of time for advertising veterans to plan, execute, budget, create, and schedule appropriate media placement. And for those media savvy students who actually watch television programs that show attempts to create advertising over a short period of time, they get a dismal picture of failure. One only has to have watched episodes of The Apprentice for the last two seasons and the 
most recent reality show, The Cut, to show allegedly intelligent and creative people given 24 hours to plan, write and design, and produce creative ad output. On all of these episodes, the work was horrible. In fact, on the most recent season of The Apprentice, Donnie Deutsche, head of the Deutsche Group, a major advertising agency, panned both competing teams' work on a Dove body lotion product declaring them all, "LOSERS!!"

The task for an advertising instructor is to find a real world advertising project that can be successfully developed within reasonable parameters of the available time and abilities of the students. The long term goal is for the students to develop team cohesion, research capabilities, written communication skills, and to appreciate that advertising is simply not only creative output, but that creative output is the last piece of a longer, carefully planned, business analysis process.

\section{HOW DO STUDENTS LEARN?}

Advertising is about communication; this includes communication about a company's brand or image or about a particular societal problem that needs to be addressed by changing the respondent's behavior. Advertising projects are also about effective communication. In the corporate world client or an academic professor has to listen to and read the project proposal while buying into the project proposal. Despite the wide-ranging benefits of using real life projects in the classroom, such projects can be overwhelming for instructors, and many shy away from the considerable workload and time commitment often required by these projects (Lopez and Lee 2005). We were some of those instructors when we first started teaching advertising. When a project involves much information, research, and effort on the students' parts, it is the same for the professor times five, six or seven depending on the number of students and/or groups.

Let us first begin with what the students already possessed regarding information. Advertising Management is an upper division marketing elective that the students can choose to fulfill their major requirements. It is part of a list of required marketing electives in which the students choose three out of the four courses. Therefore, all students in the course had already taken Principles of Marketing, Principles of Management, and two economics courses. The students had already taken a Business Communications and a two-semester Humanities course which emphasized writing skills. We knew that the students had been exposed to the basic marketing strategies of pricing, product, distribution, and promotion. They also should have learned about supply and demand, segmentation and positioning, and theories of consumer behavior. Students typically take the upper division required elective Consumer Behavior simultaneously with Advertising which is offered every semester. The Advertising course is typically comprised of junior or senior Marketing majors with an occasional Communications major from the School of Arts and Sciences. The Advertising project is an opportunity to integrate the concepts learned into active output that should demonstrate the students' potential to a prospective advertising employer. Therefore, this project relied on some prior knowledge and focused on integrating and expanding that knowledge in the context of advertising. However, the true innovation stems from the emphasis on proper written communications skills typically utilized in English writing/Humanities type courses.

According to Curran-Kelly (2005) and McCann-Nelson, Vaidyanathan and Morris (1995), the majority of business school students are classified as Divergers on Kolb's Learning styles typologies; this means that business students best respond to concrete experiences as well as an opportunity for "reflective observation." Moreover, Curran-Kelly (2005) and Johnson, Johnson and Golden (1996) state that prior research suggests that students' level of involvement is strongly related to students' perceived level of learning. Similar to Curran-Kelly (2005), we made the students aware they were the experts, and allowed them the freedom to choose a national product or service for their Advertising projects. In their everyday lives students process so many ads from a variety of media outlets such as the Internet, billboards, transit posters, television, newspapers, magazines, catalogs, and radio. They know what they like, and they know what they remember. The trick is to have students express why they remember what they remember and then have them do the necessary research to get to that point. 


\section{THE ADVERTISING PROJECT}

What is the project? It is an adaptation of Kleppner's (2002) Media Plan Report. Each of the Media Plan outline headings comes with an accompanying description of what is expected in each section. Then, an actual example of a product is included after the complete explanations of the topic heading sections. The key innovation in this outline is the inclusion of not one, but two progress reports that must be handed in by the student groups. This innovation, which requires more work on the instructor's part since he/she will have to read, grade, and correct the project three times, is critical in getting excellent final results from the students. According to Lantos (1997), a motivating professor uses extrinsic and intrinsic motivators to enhance student involvement in the course by providing complimenting and affirming feedback in class and by prompt, positive, critical feedback on graded material. According to Nicastro (1985), students crave constant feedback in the form of grades, performance evaluations and reviews. Knowing their progress gives students a sense of control and consequently, enhances their motivation (Clack and Poledink, June/July 1996, p. 3), especially to improve, if need be. Lantos (1997), also states that such feedback includes the rapid return of papers and exams and providing meaningful written comments on their work's strengths and weaknesses, with suggestions for improvement, which are later complimented if they occur. We also have individual group discussions on the progress reports so that students can question or clarify some of the feedback comments from the professor. It is worth the extra time and effort both on the students' and professors' parts to achieve better results for the assignments. The upfront effort pays off with less work at the end of the semester when professors' times are quite busy with the grading of multiple class projects and exams. The assignment is as follows:

\section{WRITTEN \& ORAL PROJECT ADVERTISING MANAGEMENT}

Groups will be formed on your own and based on mutual interest. Pick a product from an existing company and develop the media plan for the product. The only constraint while doing this project is that you must find out what the actual advertising and/or other promotional budget (s) is/are for the product. You cannot make one up on your own as if it were your wish list. The budget will determine your promotional spending, media selection, and message development. The other particulars of the project are on your syllabus.

Here is a sample outline of the media plan. It is based on careful market analysis. Follow these headings for your written and oral projects. On a separate handout will be descriptions of what material falls under these headings and an example of an actual project. You will be required to at least design (via storyboard, rough drawings) some creative output based on your market analysis. You will not be judged on how well an artist or director you are, but some planning of the creative output is required. Some of the headings may not be appropriate for your product or service. That is fine. Don't worry. You also may use "bullet points" to fill in some of the information for the headings. This is okay too! In fact, many media plans at large advertising agencies do nothing but bullet points in written reports and oral presentation slides. Brevity is acceptable in this profession.

You will be handing two different progress reports. Each progress report will include a certain number of the sections below. In order for you to complete subsequent sections, you will need to do these sections in order as listed below. Eventually, you will have the complete paper. Each progress report will be handed in as if you are turning them in for a grade. All supporting documentation, charts, graphs, tables, etc., should be included in these reports. You will then receive feedback from the instructor. You are more than welcome to include more sections in any progress report than those required below.

Media Work Plan, Part I - Marketing Analysis:

Advertising Period:

Market Description: 
Product Description:

Product Positioning:

Competition:

Seasonality: What time of year has the most sales? Why?

Geography: where is product distributed; sales are most prominent

Purchase Patterns:

\title{
Usage Patterns/First Progress will include all of these sections:
}

\author{
Pricing: \\ Distribution: \\ Trade/Consumer Promotions: \\ Marketing Objectives/Strategies: \\ Creative: \\ A. Message \\ B. Tone \\ Advertising Strategy: \\ Media Budget: \\ Media Objective: \\ Media Target Audience: \\ Media Strategy/Second Progress Report will include up to all of these sections: \\ Media Elements: Which are you choosing? Why? \\ Media Alternatives: \\ Media Schedule: Justify your responses.... \\ Creative Output:/Final Paper will include all of these sections and prior sections
}

Having to submit progress reports forces the students to start working immediately on the project. As a professor, one can rant and rave to students about starting immediately on the project because this is something that cannot be done last minute. But even if 50-60 percent of the course's grade is determined by this project (oral and written components), students tend to procrastinate. The end result of the project is usually not good and certainly not worthy to show a potential recruiter. While there are motivated students who do actually listen to the professor and get started immediately and do a fairly decent job on the project, these students are the minority. We have taught at several institutions over the last fifteen years, both public and private. It does not matter; most students would rather "blow off" the work until the last minute. We got tired of reading and listening to inferior work when we knew that the students were capable of much more. My colleagues said that we expected too much. We simply said that these are the standards that we had in college and our MBA programs. We subscribe to the minority viewpoint that proper, effectively written work should be the standard for all written coursework.

The simple addition of progress reports works beautifully for both the students and the professor. First, it motivates the students to get to work because they have a deadline. We highlight the progress report due dates on the syllabus just like an exam. They see this, and it forces the group to meet early and often to coordinate and go over the work with each other. This accelerates the exchange of ideas and preparation of the final report. The professor can decide what percentage of the grade the progress reports comprise of the final project grade. Next, the progress reports allow the instructor to stop potential disasters where information is missing completely or is "too thin" and needs to be bolstered. We write comments right on the report, and if we need to explain something in length, we write that the students should "See me (us)." We correct grammar and organization. This lets the students know how particular a professor will be as a grader. This is very important considering: (1) The students have never done anything like this before; (2) The students see the expectation levels for writing in addition to content. They now know that they will have to pay particular attention to writing and content details. 
Besides the guidelines and example that are clearly spelled out in their separate handouts of what each section should contain, the students are given grammar guidelines. We have made a list of the most common grammar mistakes we see on student papers, undergraduate and graduate. We show them the wrong way, and the correct way for everything from usage to punctuation. An example of a "Common Grammar Mistake" from our list is as follows:

- $\quad$ A company is a singular entity. The management or employees are plural. When you refer to a company in your paper, make sure you use a singular pronoun and verb when referring to it.

- $\quad$ Example: AT\&T is a long distance phone company. They tend to integrate many forms of management styles to their employees.

- $\quad$ They tend and there are incorrect usage. AT\&T is a singular company. It needs a singular pronoun, verb and possessive pronoun.

- $\quad$ Corrected example: AT\&T is a long distance phone company. It tends to integrate many forms of management styles to its employees.

- When you use a company in a paragraph and have not identified the company's employees, managers, or officers anywhere stated in a sentence, you MUST keep using singular forms of pronouns and verbs. You MUST be consistent.

They are also required to have a style/grammar textbook as part of the class textbook requirements. We simply reuse the one from their freshman humanities class or business communications course so they do not have to pay extra money for a new one. We tell them that they do not get partial credit if there is even one typo in an ad or sales brochure materials. In the real world, clients do not tolerate this; one mistake in a written or oral presentation such as spelling or grammar can cost the students their jobs, their boss' job, or the loss of a client. Sensbach and Adler (1986) advocated this philosophy when they stressed the importance that advertising courses should simulate real life with real life consequences. Effective written and oral communication skills are critical for success in every field. Typically, the oral component of a written report will include PowerPoint slides. It is just as critical in these slides to ensure perfect grammar and spelling. Students lose $1 \frac{1}{2}$ point for every punctuation mistake in their written papers, and they fail the oral presentation with one typo or grammar error in any slides. Finally, the students are given past samples of anonymous student projects. We do not tell them the grades on these projects, and we do not tell them if they are undergraduate or graduate projects. We let them make the determination of grades by comparing and contrasting the different samples. They can take the samples home and use them as guidelines as well. Many of them are taken aback when they see how much work goes into the project. We also do not stress the creative output as part of the grade for the project. Students are only required to make storyboards or a rough mock ups of ads. Many students want to spend the majority of their efforts in producing billboards, magazine ads, videos, animated streams, or brochure materials for this project, but we do not stress this as even a minor part of the grade. They eventually realize that the creative output truly comes from the business plan analysis of all of the prior sections and not just thinking of something funny off the top of their heads. The students gain valuable experience and professionalism while being guided before the final project. The professor already has the advantage by the end of the semester of being quite familiar with all of the projects. This can save the professor time by relieving pressure when mass grading occurs at the end of the semester. We keep copies of our commented progress reports on the students so we know what we are looking for each time we grade the next progress report and final written project. These progress reports indeed help the final project.

We were not always believers in using progress reports or in using a term project. Our first years teaching advertising were spent using case write-ups because we thought we did not have the time to mark the projects. We also did not believe the students had adequate time to do a good job. But when we had advertising speakers come in and ask students how they would differentiate themselves from other applicants for entry-level advertising positions, the answers given to these potential recruiters left them baffled and unimpressed. We do not have any advertising agencies that come recruiting at our current institutions so we explain to our students that marketing themselves will be critical to get into the industry. We can recommend getting co-ops and internships, but having something tangible 
in hand to present to recruiters is crucial for success. We started adapting the media plan five years ago. We first showed the media plans to key advertising executives who told us that someone who did an excellent job with the content of this type of report would be someone they would hire. The progress report idea stemmed from taking a year long seminar on making a course a writing intensive course. The seminar was taught by the heads of the English Department at our current institution. We met once every six weeks to discuss and develop different exercises with professors from various disciplines. We had different English faculty and administrative people monitor our work, and we presented the work to our peers in the seminars for more feedback. Two progress reports lead to better results than one progress report.

\section{DATA RESULTS FOR USING MULTIPLE PROGRESS REPORTS}

In terms of assessing whether the progress reports and subsequent feedback helped the students learn, (See Table 1), we asked that exact question of the students after each semester as part of our own personal feedback system. It was asked in terms of three 7-point scaled questions that were averaged together for the actual score. The question is as follows: Please indicate your general feeling about the use of progress reports and subsequent feedback in terms of the semester length project in this course: -3 to +3 with the following anchors- bad/good; unsatisfied/ satisfied; ineffective/effective. The Cronbach alpha scale reliability score was 0.93 . Over five years, 347 undergrad students were surveyed with about an even split of male and female students: 176 females, 171 males. The average age of the sample was 20.3 years. Their overall average score on these collapsed scales was 2.73 , a very positive result. T-tests were conducted to see if there were any significant gender differences between the means. Males had a mean of 2.69 while females had a mean of 2.72. No significant differences exist between these means. $(t=2.16, p<$ .15). Richardson and Swan (2003) report that students who were most satisfied with their instructors also believed that they learned more from their courses than students who were less satisfied with their instructors, indicating a relationship between instructor satisfaction and perceived learning (p. 73).

Table 1:

Assessment of Progress Report Usage Vs. Non-Usage

\begin{tabular}{|c|c|c|c|c|}
\hline & $\begin{array}{c}\text { Means Of Group } \\
\text { With Progress } \\
\text { Reports } \\
(\mathbf{n}=347) \\
\end{array}$ & $\begin{array}{c}\text { Means Of Group } \\
\text { Without Progress } \\
\text { Reports } \\
(\mathbf{n}=335)\end{array}$ & t-score & $\begin{array}{c}\begin{array}{c}\text { Significance } \\
\text { Level }\end{array} \\
\end{array}$ \\
\hline Comparison of average grades & $88.7 \%$ & $80.1 \%$ & 11.34 & $p<.001$ \\
\hline Provision of feedback $^{(1)}$ & 4.89 & 4.01 & 6.78 & $p<.05$ \\
\hline Overall quality of teaching $^{(2)}$ & 4.55 & 3.98 & 7.65 & $p<.05$ \\
\hline $\begin{array}{l}\text { General feeling about the use of progress } \\
\text { reports and subsequent feedback }\end{array}$ & 2.73 & $\mathrm{n} / \mathrm{a}$ & $\mathrm{n} / \mathrm{a}$ & $\mathrm{n} / \mathrm{a}$ \\
\hline
\end{tabular}

(1) The instructor provided helpful feedback on assignments and exams scale. Mean ranges from 1 (strongly disagree) to 5 (strongly agree).

(2) The overall quality of the instructor's teaching. Mean ranges from 1 (poor) to 5 (excellent).

(3) Only applicable for group of undergraduate students in course with progress reports. Instrument utilized three 7-point scale items ranging from -3 to +3 with the following anchors- bad/good; unsatisfied/satisfied; ineffective/effective. Overall average collapses the three scale items into an aggregate mean score.

We also compared the overall grade average for a similar group of Advertising course students who did not write progress reports, but had the same project assignment. The sample without the progress reports was comprised of 335 students with 169 female and 166 male students with an average age of 20.9 years. The mean grade average was $80.1 \%$ for this group. The grade average for the sample that used progress reports in the Advertising course was $88.7 \%$. T-tests were used to compare these two means $(t=11.34, p<.001)$ showing a significant difference between the overall grades between the two groups. Finally, comparing the differences between the two samples on two end of semester teaching evaluation scale questions showed significant differences between the students who did not have progress reports versus the ones that did. The first question was: The instructor provided helpful feedback on assignments and exams. The scale went from 1 (strongly disagree) to 5 (strongly agree). The mean of students without progress reports was a 4.01; the mean of students with progress reports was 4.89. The t-score was: $(t=6.78, p<.05)$. 
The second question was: The overall quality of the instructor's teaching. The scale went from 1 (poor) to 5 (excellent). The mean of students without progress reports was a 3.98; the mean of students with progress reports was 4.55. The t-score was: $(t=7.65, p<.05)$. These results seem to indicate better learning and results from the students who wrote progress reports. Approximately, $80 \%$ of the written comments mentioned that "the project was a lot of work, but the feedback on progress reports really helped organize our thoughts and focus our efforts to get a better grade." And 70\% of the written comments stated something to the effect of, "I'm a lousy writer; I hate doing multiple drafts of anything, but the progress reports make me a better writer.”

\section{CONCLUSIONS}

As with any term project, students seem overwhelmed by the vastness of information to be obtained and the fact they have to hand in multiple forms of the projects for grades or credit. There are always some who do nothing for a group project. There are those who complain that their other professors do not care about grammar and punctuation so why should they? We tell them that two of their fellow past students got marketing jobs in Fortune 500 companies that never recruit at their current institution of higher learning by doing this project. The students reported to us that their prospective bosses were so impressed stating the following to the students: "I have eight Wharton MBA's who don't have a clue about what you did in this report. I don't write this well!" And "We pay consultants thousands of dollars to present this information to us once a year...you did this in your undergrad class from where?!”

Finally, anyone could adopt progress reports into any project at any level. Any professor could develop a list of common grammar mistakes to hand out to their students. A professor probably does not have to have multiple progress reports for an MBA class; they are already motivated. A professor can use his/her judgment as to how many progress reports are needed. It may not seem like a revelation in terms of innovation. But what a difference in output and professionalism that can happen because of using these progress reports and grammar standards. Students benefit the most from having something tangible to give prospective employers. Our job is not only to teach, but to prepare people for careers and jobs. We believe it is a professor's responsibility to make writing as important as content. And AACSB thinks so too; progress reports help the feedback loop in individual classes so that there are measurements for the assessment of schools' learning goal of effective student written communication skills.

\section{SUGGESTIONS FOR FUTURE RESEARCH}

It is possible that further delineation of multiple progress report utilization on term projects in the classroom be investigated with the use of other variables such as the use of guest speakers who speak directly on specific aspects of the project, student critiques of fellow student projects, and individual conferences with each group to see if there are interaction effects that also enhance student grades and satisfaction with the course . The continuous review of course processes is something that all academics should be conducting. Sometimes, the most obvious practices need to be implemented AND investigated in the classroom to determine teaching and learning effectiveness. These practices when reviewed should not be dismissed.

\section{REFERENCES}

1. AACSB International-The Association to Advance Collegiate Schools of Business (2005), Eligibility Procedures and Accreditation Standards for Business Accreditation, Adopted: April 25, 2003; Revised: January 01, 2004; Revised: January 01, 2005, at http://www.aacsb.edu/accreditation/business/ AACSBSTANDARDS-Jan05-Final.pdf, accessed November 21, 2005.

2. $\quad$ Clack, Donna and Alice Poledink (1996), A Grade Is Not a Gift, Teaching Professor, (June/July), 3.

3. Curran-Kelly, Catherine (2005), Stranger in a Strange Land: Using International Student Experiences to Teach Adaptation in Global Marketing, Marketing Education Review, 15 (Summer), 55-58.

4. Johnson, Scott D., Denise M. Johnson, and Peggy A. Golden (1996), Enhancing Perceived Learning Within the Simulated Marketing Environment, Marketing Education Review, 6 (Summer), 1-9.

5. Lantos, Geoffrey P. (1997), Motivating Students: The Attitude of the Professor, Marketing Education Review, 7 (Summer), 27-38. 
6. Lopez, Tará Burnthorne and Renée Gravois Lee (2005), Five Principles for Workable Client-Based Projects: Lessons from the Trenches, Journal of Marketing Education, 27 (August) 172-189.

7. McBane, Donald A. (1996), Using Technology to Increase Feedback When Grading Assignments, Marketing Education Review, 6 (Summer), 45-58.

8. McCann-Nelson, Michelle, Rajiv Vaidyanathan, and Linda J. Morris (1995), Enhancing Learning Through Expert Systems in the Marketing Classroom: Learning Styles as a Moderating Factor, Marketing Education Review, 5 (Fall), 9-19.

9. Nicastro, Mary (1995), Teaching Generation X: A Challenge for Marketing Professors, Marketing Educator, (Summer), 3.

10. Richardson, Jennifer C. and Karen Swan (2003), Examining Social Presence in Online Courses in Relation to Students' Perceived Learning and Satisfaction, Journal of Asynchronous Learning Networks, 7, 68-88.

11. Russell, J. Thomas and W. Ronald Lane (2002), Kleppner's Advertising Procedure, Upper Saddle River, NJ: Prentice-Hall.

12. Sensbach, P.R. and R. D. Adler (1986), Advertising Courses Should Simulate Real Life, Journal of Marketing Education, 8, 66-69. 